\title{
Reducing Fat Content of Fried Potato Pellet Chips Using Carboxymethyl Cellulose and Soy Protein Isolate Solutions as Coating Films
}

\author{
Malak M. Angor ${ }^{1}$ \\ ${ }^{1}$ Al-Huson University College, Al-Balqa Applied University, Al-Huson, Jordan \\ Correspondence: Malak M. Angor, Al-Huson University College, Al-Balqa Applied University, Al-Huson, \\ Jordan. Tel: 962-797-633-048. E-mail: malakangor@yahoo.com
}

Received: January 16, 2015 Accepted: February 13, 2016 Online Published: February 15, 2016

doi:10.5539/jas.v8n3p162 URL: http://dx.doi.org/10.5539/jas.v8n3p162

\begin{abstract}
The aim of this work was to investigate the influence of different percentages of Carboxymethyl Cellulose (CMC) and Soy Protein Isolate (SPI) as coating material films for potato pellet chips during deep-fat frying on fat uptake, and sensory properties. Coating solutions of $2 \%, 6 \%, 10 \%$ and $14 \% \mathrm{w} / \mathrm{v}$ were prepared and heated to $90{ }^{\circ} \mathrm{C}$ for 5 minutes then cooled. Samples were dipped in the coating solutions followed by air drying. The treatments were fried and analyzed for fat uptake and moisture retention. Sensorial attributes were also measured. The results obtained have shown that all coating treatments were reduced oil uptake during deep fat frying. The $10 \%$ was the most effective level in reducing fat uptake for both coating films. SPI coating films was reducing fat uptake more than $\mathrm{CMC}$ for all levels. All samples were found to improve all sensorial features of potato pellet chips compared to control.
\end{abstract}

Keywords: fat uptake, coating film, potato pellet chips, carboxymethyl cellulose, soy protein isolate

\section{Introduction}

Deep-fat frying is a widely used method of cooking in commercial food processing. It is a method that enhances the flavor, texture and appearance of food products. On the other hand consumer awareness of the health implications of eating foods with a high fat content is on the increase (Ngadi et al., 2006). So one of the main problems associated with fried food is its high oil content; as a result it is associated with the high incidence of diseases such as obesity, high cholesterol levels, etc. (Varela \& Fiszman, 2011). The concern to develop healthier products that contain less fat, absorbed during industrial pre-frying and frying processes, is one of the dominant factors in the latest research prompting studies of ways to lower the oil content of fried food. Different ingredients have been proved to be effective in reducing the amount of oil absorbed by fried food. Among these using an aqueous solution forming what is generally known as an 'edible coating films' on the food to be fried (Mellema, 2003). Application of coating is therefore a promising route to reduce oil content (Ngadi et al., 2007).

However, there is no published information about the use of Carboxymethyl Cellulose and Soy Protein Isolate as coating materials to reduce moisture loss and fat uptake of potato pellet chips during deep-fat frying. Therefore, the aims of this study are to study the effect of different percentages of Carboxymethyl Cellulose (CMC) and Soy Protein Isolate (SPI) as coating material films for potato pellet chips during deep-fat frying on the level of fat uptake and sensory properties.

\section{Materials and Methods}

\subsection{Materials}

The coating materials used were CMC (under commercialmarks YO-EH, YO-M, HVEP were obtained from local market in Jordan) and SPI, glycerine, potato pellet chips (Jopellet, Jordan) and corn oil for frying (Yara oil, Jordan).

\subsection{Coating Solution Preparation}

For each coating material, four solutions of $2 \%, 6 \%, 10 \%$ and $14 \% \mathrm{w} / \mathrm{v}$ in water were prepared. Each solution was heated to $90{ }^{\circ} \mathrm{C}$ for 5 minutes then cooled to room temperature, glycerin was added at a level of $4 \% \mathrm{w} / \mathrm{v}$ to these solutions as plasticizer (Freitas et al., 2009). Potato pellet chips were dipped for 10 seconds in the coating 
solutions followed by air drying using an air blower; the dipping and drying procedures were repeated again to ensure uniform coating of the film on the products. Potato pellet chips were treated in the same procedure without using coating materials used as control.

\subsection{Frying}

All samples were fried in a commercial electrical deep-fat fryer (Emjoi power, Model UEDL-206, China) containing 2 liters corn oil at $180 \pm 2{ }^{\circ} \mathrm{C}$ for 10 seconds. A digital thermocouple (K-type, APPA-51,Taiwan) was connected to the fryer to control the temperature of the frying oil while a golden color surface of the samples product were controlled by controlling the time of fryer timer. Used oil was replaced by fresh oil after four frying batches (García et al., 2002). In each batch, twenty potato pellet chips were placed inside the frying basket. Frying was carried out by immersing the basket in the oil. After frying, samples were placed on absorbing paper towels for 5 minutes prior further test. This was done to minimize the absorption of oil due to the cooling down period (Southern, 2000). The fried samples were left to cool down to ambient conditions for 1 hour. One part of the freshly fried samples was taken immediately for sensory evaluation, while the other parts were placed in plastic bags until chemical and physical analysis. All experiments were run in duplicate and the present results are the average of the obtained results.

\subsection{Samples Analysis}

The moisture and the fat contents were determined, according to AOAC (Association Official Analytical Chemists) (2000) and each analysis was carried out in duplicate.

Moisture content was determined by an oven-drying method in which potato pellet chips samples were placed in dishes and held in an oven (Memmert, 854, Schwapach, Germany) at $105^{\circ} \mathrm{C}$ until constant weight was reached.

Fat content was determined by the Soxhlet method, which involve continuous vaporisation and condensation of petroleum ether during passage through a $5 \mathrm{~g}$, moisture-free sample placed in the extraction thimble and covered with cotton wool. After $16 \mathrm{~h}$, the extract was collected and subjected to distillation in order to collect the crude fat, which was then dried and weighed.

The data for fat and moisture were compared by calculating the fat uptake relative variation\% (FU) and moisture retention relative variation\% (MR) in the coated product relative to the uncoated one were calculated according to García et al. (2002) as follows:

$$
\begin{gathered}
F U=\left[\frac{F C \text { coated }}{F C \text { uncoated }}-1\right] \times 100 \\
M R=\left[\frac{M C \text { coated }}{M C \text { uncoated }}-1\right] \times 100
\end{gathered}
$$

A Forty sensory panel consisting of undergraduate students of the Al-Huson University Collage were evaluated samples from each treatment for sensory evaluation. The panellists were of both sexes and different ages (18-40 years). Before evaluating the samples, they were familiarised with the test procedure and use of the scoring system.

Samples were scored for general appearance, color, flavor, taste, crispiness and overall acceptability, using a descriptive nine-point hedonic scale on which 9 was 'like extremely' and 1 was 'dislike extremely', Water was provided to rinse the mouth between samples to neutralise any lingering taste from the previous sample. All treatments were evaluated in duplicate on separate occasions.

\subsection{Statistical Analysis}

Statistical analysis of data was carried out using Statistical Analysis System package (SAS Inc., 1997). The data obtained were analyzed using a Completely Randomized Design (CRD) to study the effect of treatments on the fat $\%$, moisture $\%$, fat uptake $\%$, moisture retention $\%$, and sensory scores. The significant difference of the mean was determined using Least Significant Difference (LSD) method.

\section{Results and Discussion}

The effect of different concentration of CMC coating films $(2 \%, 6 \%, 10 \%$ and $12 \%)$ and control on fat and moisture percent for deep fried potato pellet chips were ranged from $19.9 \%$ to $39.49 \%$ and $1.05 \%$ to $1.93 \%$ respectively (Table 1).

All the treatments of CMC reduced fat percent significantly $(p \leq 0.01)$ compared with control. These results were agreed with Rimac-Brnčić et al. (2004) who concluded that carboxymethyl cellulose was reduced oil content for 
coated potato strip. The lowest fat percent was obtained from 10\% CMC coating film concentration compared to all other treatments. The moisture percent for deep fried potato pellet chips coated with different concentration of CMC ranged from 1.05 to $1.93 \%$. The control treatment have the lowest moisture content $(1.05 \%)$ which have the highest fat content $(39.49 \%)$, while the highest moisture content $(1.93 \%)$ for treatment that contain $14 \%$ CMC have low fat content $24.15 \%$, and these results might be due to the increase in water-holding capacity and consequently due to prevent of moisture replacement by oil, and this is agreed with Holownia et al. (2000) who reported that using many edible coating films were reduced fat absorption and improved moisture retention in starchy products and poultry products.

Table 1. Fat and moisture content of different levels of $\mathrm{cmc}$ as coating films for deep fried potato pellet chips ${ }^{1}$

\begin{tabular}{lll}
\hline Treatments & Fat $\%$ & Moisture\% \\
\hline $2 \%$ & $30.90^{\mathrm{B}}$ & $1.10^{\mathrm{C}}$ \\
$6 \%$ & $29.40^{\mathrm{C}}$ & $1.59^{\mathrm{B}}$ \\
$10 \%$ & $19.90^{\mathrm{E}}$ & $1.65^{\mathrm{B}}$ \\
$14 \%$ & $24.15^{\mathrm{D}}$ & $1.93^{\mathrm{A}}$ \\
Control & $39.49^{\mathrm{A}}$ & $1.05^{\mathrm{C}}$ \\
\hline$P^{2}$ & $* *$ & $* *$
\end{tabular}

Note. ${ }^{1}$ Values are the means of two replicates, means with different matching letters within the same column are significantly $(*: p \leq 0.05 ; * *: p \leq 0.01)$ different according to LSD. ${ }^{2 *}: p \leq 0.05 ; * *: p \leq 0.01$.

Table 2 shows the results of fat and moisture percent due to using different levels of SPI $(2 \%, 6 \%, 10 \%$ and $14 \%$ ) as coating films and control for deep fried potato pellet chips. The fat percent ranged from 18.00 to $39.49 \%$ for all treatments. All treatments of SPI reduced fat percent significantly $(p \leq 0.01)$ compared to control. These results agreed with Dogan et al. (2005) who concluded that addition of different proteins films at different concentrations to the batter decreased the oil content of the final deep-fried product. Less oil absorption may be related to the formation of covalent links within films during heating. The most effective treatment in reducing fat percent $(18.0 \%)$ in deep-fried potato pellet chips was $10 \%$ concentration SPI compared to all other treatments. This result agreed with Rayner et al. (2000) who concluded that a solution of $10 \%$ SPI is recommended for coating foods to reduce fat intake during deep-fat frying. Moisture content was significantly ( $p$ $\leq 0.01$ ) effected increasingly by SPI coated films for deep-fried potato pellet chips ranged from 1.25 to $1.94 \%$ compared to uncoated treatment $(1.05 \%)$. The increasing in moisture content and reduction in fat absorption were due to using coating films agreed with that obtained by Freitas et al. (2009).

Table 2. Fat and moisture content of different levels of spi as coating films for deep fried potato pellet chips ${ }^{1}$

\begin{tabular}{lll}
\hline Treatments & Fat $\%$ & Moisture $\%$ \\
\hline $2 \%$ & $25.20^{\mathrm{B}}$ & $1.25^{\mathrm{D}}$ \\
$6 \%$ & $22.90^{\mathrm{C}}$ & $1.55^{\mathrm{C}}$ \\
$10 \%$ & $18.00^{\mathrm{D}}$ & $1.75^{\mathrm{B}}$ \\
$14 \%$ & $22.25^{\mathrm{C}}$ & $1.94^{\mathrm{A}}$ \\
Control & $39.49^{\mathrm{A}}$ & $1.05^{\mathrm{E}}$ \\
\hline$P^{2}$ & $* *$ & $* *$ \\
\hline
\end{tabular}

Note. ${ }^{1}$ Values are the means of two replicates, means with different matching letters within the same column are significantly $(*: p \leq 0.05 ; * *: p \leq 0.01)$ different according to LSD. ${ }^{2 *}: p \leq 0.05 ; * *: p \leq 0.01$.

The influence of different levels of CMC and SPI as coating films in reducing fat uptake which led to a higher retention of moisture content for deep fried potato pellet chips (Figure 1). As moisture content in the coated product was higher than in the uncoated one, the moisture retention was always positive for each coating films CMC and SPI which increased in the same trend up to $14 \%$ concentration. The fat uptake was always negative because the fat content of the coated sample was lower than the uncoated one. In this work, the lowest fat uptake for CMC was $-49.95 \%$ and for SPI was $-54.43 \%$. These results agreed with Rayner et al. (2000) who reported the 
effectiveness of CMC to reduce fat content (49\%) as an ingredient of coatings for akara balls. The most effective reducing fat uptake for both coating films were at level $10 \%$.

SPI coating films was reducing fat uptake more than CMC for all levels. Creusot et al. (2011) reported that the effectiveness of protein to reduce fat content as an ingredient of coatings. They connected several key points that affect both oil absorption and protein structure, especially in regards to the gel formation. The gel properties of protein gels depend on the structural characteristics of the proteins used (e.g., charge, hydrophobicity). In order to form a gel, the small protein aggregates should cluster together to form larger aggregates that will form a space-filling network.

Alternatively, the larger moisture content of the SPI film increases the surface tension with the oil, contributing to less fat uptake. García et al. (2002) reported that the reduction in oil uptake and moisture loss to the formation of a protective layer on the surface of the samples during the initial stages of frying due to thermal gelation.

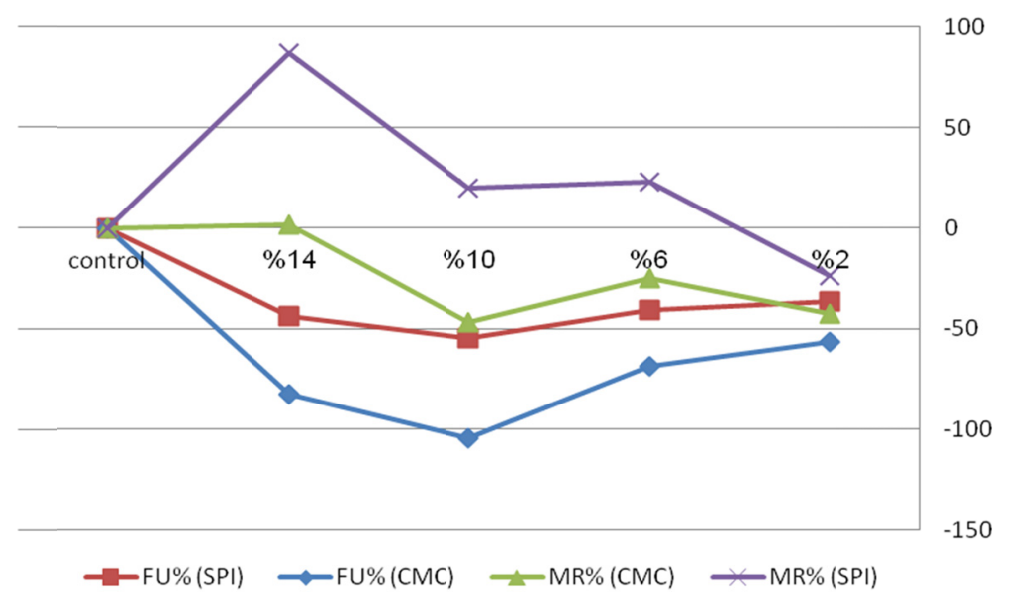

Figure 1. Fat uptake \% (FU\%) and moisture retention \% (MR\%) of diferent levels of carboxymethyl cellulose $(\mathrm{CMC})$ and soy protein isolate (SPI) as coating films for deep fried potato pellets chips

Sensorial characteristics of the marketed materials are attractive to the consumers. Descriptive nine-point hedonic scale for appearance, color, flavor, taste, crispy, and overall acceptability of the control (uncoated), CMC and SPI as coating films for deep fried potato pellet chips are shown in Tables 3 and 4.

All coated treatments (CMC and SPI) were improved all sensory attributes score comparing to the control. The scores of appearance and color of the coating samples with CMC (Table 3) ranged from 7.65 to 8.2 and 7.9 to 8.3 respectively, and they were found between the ranges of like very much to like.

This may be due to the factor that most people like potato pellet chips at different range of color, there were no significant $(p>0.05)$ differences between them, while the scores for these treatments were higher than control. Tran et al. (2007) reported that color is important factor in the qualified processing of French fries and potato chips.

The other attributes scores of flavor, taste and crispy of the coating samples with CMC (Table 3) were ranged from 7.2 to $8,7.2$ to 8.45 and 7.6 to 8.2 respectively, there were no significant $(p>0.05)$ differences between them, while the scores for these treatments were higher than control. These results were agreed with Kilincceker et al. (2009), they concluded that the smell, taste and flavor of the samples were improved by using coating materials compared to uncoated sample, and the desired color formed. 
Table 3. Means of sensory evaluation scores of different levels of $\mathrm{cmc}$ as coating films for deep fried potato pellet chips $^{1}$

\begin{tabular}{lllllll}
\hline Treatments & Appearance & Color & Flavor & Taste & Crispy & Overall acceptability \\
\hline $2 \%$ & $7.95^{\mathrm{AB}}$ & $8.10^{\mathrm{AB}}$ & $7.20^{\mathrm{B}}$ & $7.20^{\mathrm{BC}}$ & $7.60^{\mathrm{A}}$ & $7.35^{\mathrm{BC}}$ \\
$6 \%$ & $8.20^{\mathrm{A}}$ & $8.30^{\mathrm{A}}$ & $8.00^{\mathrm{A}}$ & $7.91^{\mathrm{AB}}$ & $8.20^{\mathrm{A}}$ & $8.19^{\mathrm{A}}$ \\
$10 \%$ & $8.20^{\mathrm{A}}$ & $8.30^{\mathrm{A}}$ & $8.00^{\mathrm{A}}$ & $7.90^{\mathrm{AB}}$ & $8.20^{\mathrm{A}}$ & $8.20^{\mathrm{A}}$ \\
$14 \%$ & $8.10^{\mathrm{A}}$ & $8.20^{\mathrm{A}}$ & $7.20^{\mathrm{B}}$ & $8.45^{\mathrm{A}}$ & $8.2^{\mathrm{A}}$ & $7.90^{\mathrm{AB}}$ \\
Control & $7.20^{\mathrm{B}}$ & $7.40^{\mathrm{B}}$ & $6.70^{\mathrm{B}}$ & $6.50^{\mathrm{C}}$ & $6.70^{\mathrm{B}}$ & $6.90^{\mathrm{C}}$ \\
$P^{2}$ & $*$ & $*$ & $* *$ & $* *$ & $* *$ & $* *$ \\
\hline
\end{tabular}

Note. ${ }^{1}$ Each mean is the average of 11 readings, where 9 refer to like extremely, 5 neither like or dislike and 1 refers to dislike extremely. Values within the same column followed by different letter are significantly $(*: p \leq 0.05 ; * *: p$ $\leq 0.01$ ) different according to LSD. ${ }^{2} \mathrm{~ns}: p>0.05 ;{ }^{*}: p \leq 0.05 ; * *: p \leq 0.01$.

The overall acceptability scores of the coated samples with CMC (Table 3) were found between the ranges of like very much to like, while the uncoated sample had the lowest value score for overall acceptability compared to all coated treatments, but the differences between all treatments of potato pellet chips for overall acceptability were small. These results were agreed with Salvador et al. (2008), they concluded that the differences between the coated and uncoated samples were generally small but significant in some cases.

All sensory attributes had the best score at $10 \%$ concentration of CMC as a coating film compared to all treatments. The Sensorial characteristics for all treatments of SPI film (Table 4) had nearly the same trend as CMC coating films for deep fried potato pellet chips (Table 3). Jooyandeh (2011) reported that SPI as edible coatings film can improve appearance of a product by adding color or gloss, making it more appealing to consumers.

Table 4. Means of sensory evaluation scores of different levels spi as coating films for deep fried potato pellet chips $^{1}$

\begin{tabular}{lllllll}
\hline Treatments & Appearance & Color & Flavor & Taste & Crispy & Overall acceptability \\
\hline $2 \%$ & $7.98^{\mathrm{AB}}$ & $8.10^{\mathrm{ABC}}$ & $7.20^{\mathrm{A}}$ & $7.10^{\mathrm{BC}}$ & $8.05^{\mathrm{A}}$ & $7.20^{\mathrm{BC}}$ \\
$6 \%$ & $8.25^{\mathrm{A}}$ & $8.20^{\mathrm{AB}}$ & $7.20^{\mathrm{A}}$ & $7.00^{\mathrm{BC}}$ & $8.00^{\mathrm{A}}$ & $7.60^{\mathrm{AB}}$ \\
$10 \%$ & $8.20^{\mathrm{A}}$ & $8.30^{\mathrm{A}}$ & $7.50^{\mathrm{A}}$ & $8.00^{\mathrm{A}}$ & $8.50^{\mathrm{A}}$ & $8.20^{\mathrm{A}}$ \\
$14 \%$ & $7.99^{\mathrm{AB}}$ & $7.66^{\mathrm{BC}}$ & $7.30^{\mathrm{A}}$ & $7.30^{\mathrm{AB}}$ & $8.20^{\mathrm{A}}$ & $7.80^{\mathrm{AB}}$ \\
Control & $7.20^{\mathrm{B}}$ & $7.40^{\mathrm{C}}$ & $6.79^{\mathrm{A}}$ & $6.50^{\mathrm{C}}$ & $6.90^{\mathrm{B}}$ & $6.90^{\mathrm{C}}$ \\
\hline$P^{2}$ & $*$ & $*$ & $\mathrm{~ns}$ & $* *$ & $* *$ & $* *$
\end{tabular}

Note. ${ }^{1}$ Each mean is the average of 11 readings, where 9 refer to like extremely, 5 neither like or dislike and 1 refers to dislike extremely. Values within the same column followed by different letter are significantly $(*: p \leq 0.05 ; * *: p$ $\leq 0.01$ ) different according to LSD. ${ }^{2} \mathrm{~ns}: p>0.05 ; *: p \leq 0.05 ; * *: p \leq 0.01$.

\section{Conclusions}

Using CMC and SPI in different concentration as coating films for potato pellet chips were reduced oil uptake during deep fat frying. The most effective level in reducing fat uptake for CMC was (-49.95\%) and for SPI was $(-54.43 \%)$ at $10 \%$ for both. SPI coating films was reducing fat uptake more than CMC for all levels.

A sensory evaluation on quality of the products is important. All coated treatments were improved all sensorial features of potato pellet chips compared to control.

\section{References}

Akdeniz, N., Sahin, S., \& Sumnu, G. (2006). Functionality of batters containing different gums for deep-fat frying of carrot slices. Journal of Food Engineering, 75, 522-526. http://dx.doi.org/10.1016/j.jfoodeng.2005.04.035

Albert, S., \& Mittal, G. (2002). Comparative evaluation of edible coating to reduce fat uptake in a deep-fried 
cereal product. Food Research International, $35, \quad$ 445-458. http://dx.doi.org/10.1016/S0963-9969(01)00139-9

AOAC. (2000). Official methods of analysis (17th ed.). Washington DC: Association of Official Analytical Chemists.

Creusot, N., Wierenga, P. A., Laus, M. C., Giuseppin, M. L. F., \& Gruppen, H. (2011). Rheological properties of patatin gels compared with beta-lactoglobulin ovalbumin, and glycinin. Journal of the Science of Food and Agriculture, 91(2), 253-261.

Dogan, S., Sahin, S., \& Sumnu, G. (2005). Effects of batters containing different protein types on the quality of deep-fat-fried chicken nuggets. European Food Research Technology, 220, 502-508. http://dx.doi.org/10.1007/s00217-004-1099-7

Freitas, D., Berbari, S., Prati, P., Fakhouri, F., Queiroz, F., \& Vicente, E. (2009). Reducing of fat uptake in cassava product during deep-fat frying. Journal of Food Engineering, 94, 390-394. http://dx.doi.org/10.1016/j.jfoodeng.2009.04.005

García, M., Ferrero, C., Bertola, N., Martino, M., \& Zaritzky, N. (2002). Edible coatings from cellulose to reduce oil uptake in fried products. Innovative Food Science and Emerging Technologies, 3, 391-397. http://dx.doi.org/10.1016/S1466-8564(02)00050-4

Holownia, K., Chinnan, M., Erickson, M., \& Mallikarjunan, P. (2000). Quality evaluation of edible film-coated chicken strips and frying oils. Journal of Food Science, 65(6), 1087-1090. http://dx.doi.org/10.1111/j.1365-2621.2000.tb09423.x

Jooyandeh, H. (2011). Whey Protein Films and Coatings: A Review. Pakistan Journal of Nutrition, 10(3), 296-301. http://dx.doi.org/10.3923/pjn.2011.296.301

Kilincceker, O., Dogan, I., \& Kucukoner, E. (2009). Effect of edible coatings on the quality of frozen fish fillets. LWT-Food Science and Technology, 42, 868-873. http://dx.doi.org/10.1016/j.lwt.2008.11.003

Mah, E., Price, J., \& Brannan, R. (2008). Reduction of oil absorption in deep-fried, battered, and breaded chicken patties using WPIas a postbreading dip: Effect on lipid and moisture content. Journal of Food Science, 73(8), S412-417. http://dx.doi.org/10.1111/j.1750-3841.2008.00902.x

Mellema, M. (2003). Mechanism and reduction of fat uptake in deep-fat fried foods. Trends in Food Science and Technology, 14(9), 364-373. http://dx.doi.org/10.1016/S0924-2244(03)00050-5

Ngadi, M., Dirani, K., \& Oluka, S. (2006). Mass transfer characteristics of chicken nuggets. International Journal of Food Engineering, 2(3), 1-16. http://dx.doi.org/10.2202/1556-3758.1071

Ngadi, M., Li, Y., \& Oluka, S. (2007). Quality changes in chicken nuggets fried in oils with different degrees of hydrogenation. LWT-Food Science and Technology, 40, 1784-1791. http://dx.doi.org/10.1016/j.lwt.2007.01.004

Rayner, M., Ciolfi, V., Maves, B., Stedman, P., \& Mitta, L. G. (2000). Development and application of soy-protein films to reduce fat intake in deep-fried foods. Journal of the Science of Food and Agriculture, 80, 777-782. http://dx.doi.org/10.1002/(SICI)1097-0010(20000501)80:6\%3C777::AID-JSFA625\%3E3.0. $\mathrm{CO} ; 2-\mathrm{H}$

Rimac-Brnĉić, S., Lelas, V., Rade, D., \& Simundic, B. (2004). Decreasing of oil absorption in potato strips during deep fat frying. Journal of Food Engineering, 64, 237-241. http://dx.doi.org/10.1016/j.jfoodeng.2003.10.006

Salvador, A., Sanz, T., \& Fiszman, S. (2008). Performance of methyl cellulose in coating batters of fried products. Food Hydrocolloid, 22, 1062-1067. http://dx.doi.org/10.1016/j.foodhyd.2007.05.015

SAS. (1997). SAS User's Guide in Statistics (7th ed.). SAS Institute, Inc., Cary, NC, USA.

Southern, C., Chen, X., Farid, M., Howard, B., \& Eyres, L. (2000). Determining internal oil uptake and water content of fried thin potato crisps. Food and Bioproduct Processing, 78(3), 119-125. http://dx.doi.org/10.1205/096030800532851

Tran, T., Chen, X., \& Southern, C. (2007). Reducing oil content of fried potato crisps considerably using a 'sweet' pre-treatment technique. Journal of Food Engineering, 80(2), 719-726. http://dx.doi.org/10.1016/j.jfoodeng.2006.06.031

Varela, P., \& Fiszman, S. (2011). Hydrocolloids in fried foods: A review. Food Hydrocolloid, 25, 1801-1812. 
http://dx.doi.org/10.1016/j.foodhyd.2011.01.016

\section{Copyrights}

Copyright for this article is retained by the author(s), with first publication rights granted to the journal.

This is an open-access article distributed under the terms and conditions of the Creative Commons Attribution license (http://creativecommons.org/licenses/by/3.0/). 